\title{
Vitamin D Levels, Physical and Biochemical Characteristics of South East Asian Patients with Osteoporotic Hip Fractures
}

\author{
Manju Chandran, ${ }^{1}$ Tet Sen Howe, ${ }^{2}$ Seo Kiat Goh, ${ }^{2} \mathrm{HH} \mathrm{Li},{ }^{3}$ Alvin Ng, ${ }^{4}$ Rong Fang Zhang, ${ }^{1}$ Joyce Koh ${ }^{2}$ \\ ${ }^{1}$ Osteoporosis and Bone Metabolism Unit, Department of Endocrinology, Singapore General Hospital, Singapore \\ ${ }^{2}$ Department of Orthopedic Surgery, Singapore General Hospital, Singapore \\ ${ }^{3}$ Biostatistics Unit, Department of Clinical Research, Singapore General Hospital, Singapore \\ ${ }^{4}$ Mount Elizabeth Medical Centre, Novena, Singapore
}

\begin{abstract}
Objective. Limited information exists on the physical characteristics, bone mineral density (BMD), 25-hydroxyvitamin D $[25(\mathrm{OH}) \mathrm{D}]$ levels and other biochemical parameters in patients with hip fractures in Asia. We aimed to explore whether these parameters differ between trochanteric and femoral neck (cervical) hip fractures in Singaporean patients.

Methodology. 275 patients with osteoporotic hip fractures were evaluated. Multivariate regression models were used to investigate the relationship between physical characteristics, biochemical parameters, renal function, BMD and type of hip fracture.

Results. The mean 25(OH)D level noted was $20.4(8.1) \mathrm{ng} / \mathrm{mL}$. Fifty percent of patients had levels less than $20 \mathrm{ng} / \mathrm{mL}$. Patients with trochanteric fractures were heavier than those with cervical fractures $(p=0.021)$. Logistic regression analysis showed that males were more likely to have trochanteric fractures $(\mathrm{OR}=1.79,95 \% \mathrm{Cl} 1.03-3.11)$, and females with trochanteric fractures were older than those with cervical fractures $(\mathrm{OR}=0.97,95 \% \mathrm{Cl} 0.94-1.00)$.

Conclusion. Vitamin D deficiency was prevalent in half of our population of hip fracture patients. Trochanteric fractures were more common than cervical fractures in men and in older women. In contrast to findings noted in Caucasian populations, neither BMD nor other bone metabolic parameters examined were associated with the preferential occurrence of one type of osteoporotic hip fracture over the other.
\end{abstract}

Keywords: 25(OH)D, iPTH, hip fracture type, South East Asia, metabolic bone parameters

\section{INTRODUCTION}

Osteoporotic fractures are associated with significant morbidity and mortality in the elderly. The vitamin Dparathyroid hormone (PTH) axis plays an important role in bone health and in the pathogenesis of osteoporotic fractures. The 2 major hip fracture types-femoral neck (cervical) and trochanteric-have been found to differ in etiology and pathophysiology. Previous studies have shown that the structural and material properties of the proximal femur determine the type of hip fracture. ${ }^{1,2}$ Patients with trochanteric hip fractures have been found to have lower serum vitamin D levels compared to patients with femoral neck fractures. ${ }^{3}$ Apart from studies done involving Caucasians, there is a paucity of information on other populations about the relationship of vitamin D levels and hip fracture subtypes; the interplay between $25(\mathrm{OH}) \mathrm{D}$, intact PTH (iPTH), calcium and phosphorus; the impact of renal insufficiency; and the effect of premorbid ambulatory status on hip fracture type. ${ }^{4}$

\section{METHODS}

In our hospital, the hip fracture pathway was established to provide streamlined, cost-effective and timely care. All patients with hip fractures are enrolled into the pathway. They undergo a standard array of laboratory tests done in the fasting state within 24 to 48 hours from admission. These include full blood count, serum total calcium, albumin, 25(OH)D, iPTH, phosphorus, creatinine, thyroid function and liver function tests. All laboratory analyses are performed on the day that blood is drawn. All patients above the age of 50 who have suffered an osteoporotic fragility fracture are also offered inclusion in an osteoporosis disease management program, aimed to prevent the occurrence of a second fragility fracture through the judicious combination of appropriate medications, physiotherapy and dedicated nurse manager follow up. At the time of recruitment, medical information including demographic characteristics, pre-fracture ambulatory status, previous history of fractures, and
ISSN 0857-1074

Printed in the Philippines

Copyright (C) 2012 by the JAFES

Received November 15, 2012. Accepted November 22, 2012.
Corresponding author: Manju Chandran, MD

President-Endocrine and Metabolic Society of Singapore

Senior Consultant and Director, Osteoporosis and Bone Metabolism Unit

Department of Endocrinology

Singapore General Hospital

Outram Road, Singapore 169608

Tel. No.: (65)63214654

Email:manju.chandran@sgh.com.sg 
history of calcium and vitamin D supplementation is obtained. The program only recruits patients who have a clearly established osteoporotic fragility fracture and excludes those with pathologic fractures due to primary or metastatic bone cancer, multiple myeloma, Paget's disease or other metabolic bone disease.

For this particular study, we evaluated 275 patients with fragility fracture of the femoral neck or trochanteric region who were recruited into the program between April 2009 and January 2010. BMD data was available in 188 (68.4\%) of the patients. Information on fragility fractures in the past was derived from the history obtained by the nurse managers and by review of X-ray reports. Estimated creatinine clearance of $50 \mathrm{~mL} / \mathrm{min}$ or less (calculated using the Cockcroft and Gault method) was taken as the threshold for delineating renal failure, as this has been noted to be the level below which there is impaired hydroxylation of $25(\mathrm{OH}) \mathrm{D}$ to $1,25(\mathrm{OH}) 2$ vitamin $\mathrm{D}$ $[1,25(\mathrm{OH}) 2 \mathrm{D}] .{ }^{5}$ Vitamin $\mathrm{D}$ levels were considered insufficient and deficient if levels were between 20 to 30 $\mathrm{ng} / \mathrm{mL}$ or less than $20 \mathrm{ng} / \mathrm{mL}$, respectively. Secondary hyperparathyroidism was defined as serum iPTH more than $6.2 \mathrm{pmol} / \mathrm{L}$, the upper limit of the laboratory reference range. These definitions are based on current recommendations. ${ }^{6,7}$ Ethical approval to conduct this retrospective study was obtained from the Centralized Institutional Review Board (CIRB) of our institution. The study conforms to the provisions of the World Medical Association Declaration of Helsinki.

\section{Laboratory analysis}

Laboratory tests included serum creatinine, albumin, total calcium, inorganic phosphate, liver enzymes, iPTH and 25(OH)D. Albumin-corrected calcium (Ca) in mmol/L was calculated using the following formula:

Corrected $\mathrm{Ca}=(40-$ serum albumin $) \times 0.02+$ measured total $\mathrm{Ca}$

Serum 25(OH)D was measured as per routine practice by radioimmunoassay (Diasorin, Inc., Stillwater, Minnesota, USA) after extraction with acetonitrile. The intra-assay coefficient of variation $(\mathrm{CV})$ of the assay is $11.7 \%$ at 8.6 $\mathrm{ng} / \mathrm{mL}, 10.5 \%$ at $22.7 \mathrm{ng} / \mathrm{mL}, 8.6 \%$ at $33 \mathrm{ng} / \mathrm{mL}$ and $12.5 \%$ at $49 \mathrm{ng} / \mathrm{mL}$. The total imprecision $\mathrm{CV}$ is $9.4 \%, 8.2 \%, 9.1 \%$, and $11 \%$, respectively at these 4 serum concentrations.

Serum iPTH was measured on the Beckman Dxl 800 analyzer using a two-site sandwich immunoenzymatic chemiluminescent assay. The assay uses a monoclonal anti-PTH antibody conjugated to alkaline phosphatase and paramagnetic particles coated with a goat polyclonal anti$\mathrm{PTH}$ antibody. The CV of the assay is less than 3\% for iPTH levels between 2 to $66 \mathrm{pmol} / \mathrm{L}$, and the inter-assay $\mathrm{CV}$ is less than $7 \%$ for iPTH between 2 to $80 \mathrm{pmol} / \mathrm{L}$.

\section{Bone mineral density}

BMD at the non-fractured hip and the lumbar spine (L1 to L4) was measured at our center by dual-energy X-ray absorptiometry (DXA) technology (Hologic Discovery W, Hologic, Waltham, Massachusetts, USA). Male and female ethnic-specific reference databases were used to calculate the $\mathrm{T}$ scores. The short-term in vivo precision $(\mathrm{CV})$ at our hospital is $0.95+/-0.21 \%$ for the spine and $1.20+/-0.32 \%$ for the femoral neck.

\section{Statistical analysis}

The data was analysed using the statistical software STATA (Version 10, StataCorp, College Station, Texas, USA). Continuous variables were reported as mean +/- SD and categorical variables as percentages. Comparisons of continuous data between groups were performed using Student's t-test for data following normal distribution, and Mann-Whitney $U$ test for variables not following normal distribution. Comparison between categorical variables was performed using the Fisher's exact test. Correlation between two continuous covariates was estimated by Pearson's or Spearman's rho for normally and nonnormally distributed data, respectively. Logistic regression was performed to determine the association between hip fracture type (dependent variable) and iPTH, 25(OH) D, calcium, phosphorus, and other demographic and clinical variables (age, gender, premorbid ambulatory status, presence of renal failure and calcium and vitamin D supplement intake). Two sided p-values $<0.05$ were considered significant.

\section{RESULTS}

Of the 275 patients, 205 (74.8\%) were women. Information about demographics and other parameters are shown in Table 1. The mean 25(OH)D level was $20.4 \mathrm{ng} / \mathrm{mL}$. There was no difference between the mean $25(\mathrm{OH}) \mathrm{D}$ levels in men and women. $24.8 \%$ of the patients had a previous fragility fracture. Among those with a previous history of a hip fracture, $16.7 \%$ had a femoral neck fracture, while 11 $\%$ had a trochanteric fracture. These differences were not found to be statistically significant.

Compared to those with femoral neck fractures, patients with trochanteric fractures were heavier $(p=0.021)$. However, logistic regression analysis did not find any significant effect of weight in the development of trochanteric fractures (OR=1.00, 95\% CI 0.99-1.01). Trochanteric fractures were more common in males than in females $(p=0.045)$. Logistic regression also showed that male patients tended to have more trochanteric fractures (OR=1.79, 95\% CI 1.03-3.11). There was no correlation between any of the other parameters (T-scores or Z-scores at the total hip or neck of the femur, 25(OH)D levels, 
corrected calcium, iPTH, serum phosphorus, premorbid ambulatory status, calcium supplement intake, vitamin D supplements, presence of renal insufficiency or previous fracture history) with the type of hip fracture (Table 2).

Table 1. Demographic and clinical characteristics of patients with hip fractures, $N=275$, Singapore.

\begin{tabular}{|c|c|c|}
\hline Factors & $\begin{array}{c}\text { Frequency } \\
\text { or value }\end{array}$ & Percentage \\
\hline \multicolumn{2}{|l|}{ Gender } & - \\
\hline Male & 70 & 25.4 \\
\hline Female & 205 & 74.5 \\
\hline \multicolumn{3}{|l|}{ Race } \\
\hline Chinese & 228 & 82.9 \\
\hline Malay & 23 & 8.4 \\
\hline Indian & 22 & 8 \\
\hline Others & 2 & 0.7 \\
\hline \multicolumn{3}{|l|}{ Type of fracture } \\
\hline Trochanteric & 106 & 38.6 \\
\hline Femoral neck & 169 & 61.5 \\
\hline \multicolumn{3}{|l|}{ Premorbid ambulatory status } \\
\hline Ambulatory independent & 87 & 31.6 \\
\hline Uses walking aid & 84 & 30.6 \\
\hline Bedbound & 2 & 0.7 \\
\hline Wheel chair bound & 8 & 2.9 \\
\hline Prosthesis & 1 & 0.4 \\
\hline Unknown & 93 & 33.8 \\
\hline Previous fracture & 69 & 25.1 \\
\hline Calcium supplement intake & 90 & 32.7 \\
\hline Vitamin D supplement intake & 83 & 30.2 \\
\hline Mean 25(OH)D (SD) at baseline, $\mathrm{ng} / \mathrm{mL}$ & $20.4(8.1)$ & - \\
\hline Male, $\mathrm{ng} / \mathrm{mL}$ & $21.1(8.2)$ & - \\
\hline Female, $\mathrm{ng} / \mathrm{mL}$ & $20.1(8.1)$ & - \\
\hline \multicolumn{3}{|l|}{ 25(OH)D level } \\
\hline Deficient, less than $20 \mathrm{ng} / \mathrm{mL}$ & 132 & 50.2 \\
\hline Insufficient, 20 to $30 \mathrm{ng} / \mathrm{mL}$ & 100 & 38 \\
\hline Sufficient, more than $30 \mathrm{ng} / \mathrm{mL}$ & 31 & 11.8 \\
\hline Median iPTH (range), pmol/L & $4.9(0.5-200.0)$ & - \\
\hline \multicolumn{3}{|c|}{ iPTH level among patients with $25(\mathrm{OH}) \mathrm{D}$ deficiency } \\
\hline Elevated, $6.2 \mathrm{pmol} / \mathrm{L}$ or greater & 33 & 35.1 \\
\hline Normal, less than $6.2 \mathrm{pmol} / \mathrm{L}$ & 61 & 64.9 \\
\hline \multicolumn{3}{|c|}{ iPTH level among patients with $25(\mathrm{OH}) \mathrm{D}$ insufficiency } \\
\hline Elevated, $6.2 \mathrm{pmol} / \mathrm{L}$ or greater & 17 & 21.5 \\
\hline Normal, less than $6.2 \mathrm{pmol} /$ & 62 & 78.5 \\
\hline Mean corrected calcium (SD), $\mathrm{mmol} / \mathrm{L}$ & $2.32(0.11)$ & - \\
\hline
\end{tabular}

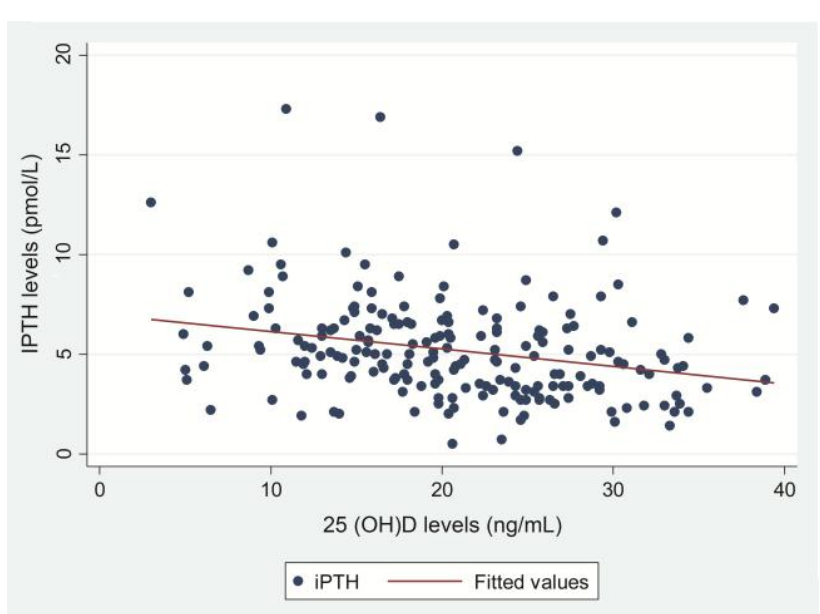

Figure 1. Scatter plot of iPTH versus $25(\mathrm{OH}) \mathrm{D}$ among all patients

Women with trochanteric fractures were older than those with femoral neck fractures $(p=0.042)$. This was also evident in the logistic regression analysis (OR $=0.97,95 \%$ $\mathrm{CI}=0.94-1.00)$. There were no differences between any of the parameters in men with femoral neck and trochanteric fractures (results of analysis not shown).
There was a significant inverse correlation between iPTH and $25(\mathrm{OH}) \mathrm{D}$ levels in the entire population of patients $(\mathrm{r}=-0.261 ; p<0.001)$ (Figure 1$)$. Linear regression analysis showed that for every $1 \mathrm{ng} / \mathrm{mL}$ decrease in $25(\mathrm{OH}) \mathrm{D}$, iPTH levels increased by $0.08 \mathrm{pmol} / \mathrm{L}$ (coefficient $=-0.08$, CI: -0.13 to -0.04), after adjusting for age and gender.

Table 2. Comparison of characteristics according to hip fracture type

\begin{tabular}{|c|c|c|c|}
\hline \multirow[b]{2}{*}{ Factors } & \multicolumn{2}{|c|}{$\begin{array}{l}\text { Type of current hip } \\
\text { fracture }\end{array}$} & \multirow[b]{2}{*}{$p$ value } \\
\hline & Trochanteric & $\begin{array}{l}\text { Neck of } \\
\text { femur }\end{array}$ & \\
\hline Mean age (SD), yr & $78.3(10.5)$ & $77.6(9.6)$ & 0.586 \\
\hline Mean height (SD), $\mathrm{cm}$ & $153.8(8.6)$ & $151.5(8.8)$ & 0.277 \\
\hline Mean weight (SD), kg & $57.9(12.9)$ & $51.5(10.7)$ & 0.021 \\
\hline Mean T-score at $\mathrm{TH}^{\mathrm{a}}(\mathrm{SD})$ & $-2.7(1.6)$ & $-2.9(1.1)$ & 0.618 \\
\hline Mean T-score at $\mathrm{NOF}^{\mathrm{b}}$ (SD) & $-2.7(1.8)$ & $-3.0(1.1)$ & 0.395 \\
\hline Mean 25(OH)D (SD), ng/mL & $21.1(8.8)$ & $19.9(7.6)$ & 0.225 \\
\hline $\begin{array}{l}\text { Mean corrected calcium } \\
\text { (SD), } \mathrm{mmol} / \mathrm{L}\end{array}$ & $2.3(0.1)$ & $2.3(0.1)$ & 0.671 \\
\hline Median iPTH (range), pmol/L & $\begin{array}{l}5.0 \\
(1.6-45.4)\end{array}$ & $\begin{array}{l}4.9 \\
(0.5-200.0)\end{array}$ & 0.636 \\
\hline $\begin{array}{l}\text { Median serum phosphorus } \\
\text { (range), } \mathrm{mmol} / \mathrm{L}\end{array}$ & $\begin{array}{l}1.1 \\
(0.7-2.2)\end{array}$ & $\begin{array}{l}1.2 \\
(0.7-1.7)\end{array}$ & 0.974 \\
\hline Gender & & & 0.045 \\
\hline Male & 36 & 34 & \\
\hline Female & 72 & 133 & \\
\hline Race & & & 0.836 \\
\hline Chinese & 89 & 139 & \\
\hline Malay & 8 & 15 & \\
\hline Indian & 9 & 13 & \\
\hline Others & 0 & 2 & \\
\hline $\begin{array}{l}\text { Premorbid ambulatory } \\
\text { status }\end{array}$ & & & 1.000 \\
\hline Ambulatory independent & 38 & 49 & \\
\hline Uses walking aid & 37 & 47 & \\
\hline Calcium supplements & & & 0.693 \\
\hline Yes & 33 & 57 & \\
\hline No & 73 & 112 & \\
\hline Vitamin D supplements & & & 0.893 \\
\hline Yes & 31 & 52 & \\
\hline No & 75 & 117 & \\
\hline iPTH among all patients & & & 0.425 \\
\hline Elevated, $6.2 \mathrm{pmol} / \mathrm{L}$ or greater & 26 & 30 & \\
\hline Normal, less than $6.2 \mathrm{pmol} / \mathrm{L}$ & 57 & 88 & \\
\hline $\begin{array}{l}\text { iPTH among patients with } \\
\text { vitamin D deficiency }\end{array}$ & & & 0.825 \\
\hline Elevated, $6.2 \mathrm{pmol} / \mathrm{L}$ or greater & 12 & 21 & \\
\hline Normal, less than $6.2 \mathrm{pmol} / \mathrm{L}$ & 25 & 36 & \\
\hline $\begin{array}{l}\text { iPTH among patients with } \\
\text { vitamin D insufficiency }\end{array}$ & & & 0.164 \\
\hline Elevated, $6.2 \mathrm{pmol} / \mathrm{L}$ or greater & 10 & 7 & \\
\hline Normal, less than $6.2 \mathrm{pmol} / \mathrm{L}$ & 23 & 39 & \\
\hline Renal failure & & & 0.321 \\
\hline Yes & 23 & 46 & \\
\hline No & 83 & 123 & \\
\hline Previous fracture $^{c}$ & & & 0.390 \\
\hline Yes & 23 & 45 & \\
\hline No & 80 & 123 & \\
\hline
\end{tabular}

\section{DISCUSSION}

Our study is the first from a South East Asian country exploring the effect of physical, demographic, as well as bone metabolic parameters on the different types of hip fractures. Though the majority of the patients in the study had low levels of $25(\mathrm{OH}) \mathrm{D}$ as defined by currently accepted standards, contrary to the only two previous studies on the subject, neither $25(\mathrm{OH}) \mathrm{D}$ levels, blunted parathyroid response or hyperparathyroidism associated with low levels of $25(\mathrm{OH}) \mathrm{D}$ correlated with the type of hip fracture. 
Vitamin D status and iPTH level and their relation to bone health in patients from various ethnicities and geographic areas have gained increasing interest among scientists. Varying effects of $25(\mathrm{OH}) \mathrm{D}$ concentrations on BMD have been reported among community-dwelling South East Asian and Far East Asian women with no previous history of osteoporosis. $^{8-14}$ There is conflicting evidence with regard to the association of vitamin $\mathrm{D}$ deficiency with the occurrence of osteoporotic fractures..$^{15-20}$ A study from Hong Kong showed that hypovitaminosis D was common among elderly patients with femoral neck fractures. ${ }^{21} \mathrm{~A}$ similar study on Japanese postmenopausal women living in Hawaii did not find any significant association between $25(\mathrm{OH}) \mathrm{D}$ and either vertebral or nonvertebral fractures. ${ }^{22}$ In our study, $88.2 \%$ of the population had $25(\mathrm{OH}) \mathrm{D}$ levels less than $30 \mathrm{ng} / \mathrm{mL}$. Given the lack of an age- and gendermatched control group without hip fractures, it is difficult to ascertain whether the prevalence of vitamin D insufficiency is higher in patients with osteoporotic fractures compared to those without. An earlier study in patients with low BMD done in Singapore did not show any correlation between low 25(OH)D levels and osteoporotic fractures. ${ }^{23}$

We did not find any difference in the 25(OH)D levels between patients with femoral neck and trochanteric fractures, in agreement with a previously published study. ${ }^{24}$ In contrast, a study done in Crete found that patients with trochanteric fractures had lower levels of 25(OH)D. ${ }^{4}$ An excess of trochanteric over femoral neck fractures was found in patients with hypovitaminosis D and secondary hyperparathyroidism, compared to those with "functional hypoparathyroidism," a condition characterized by vitamin D deficiency with no evidence of adequate parathyroid response. ${ }^{25}$ Although we found a significant negative correlation between $25(\mathrm{OH}) \mathrm{D}$ and iPTH levels in both groups of fracture patients, the prevalence of both secondary hyperparathyroidism and "functional hypoparathyroidism" in patients with insufficient or deficient $25(\mathrm{OH}) \mathrm{D}$ levels was quite similar between the two types of fracture patients. Likewise, there was no preferential occurrence of either type of fracture in both the secondary hyperparathyroid and the "functional" hypoparathyroid patients. This finding is relevant in the context of recent findings that racial and geographic differences modulate the effects of low vitamin D status on bone mass and other parameters of bone metabolism. ${ }^{26-28}$

Singapore is a South East Asian country with a unique ethnic population mix of Chinese (76.8\%), Malay (13.9\%), Indian $(7.9 \%)$, and others $(1.4 \%){ }^{29}$ Racial differences in fracture rates and vitamin D levels have been shown to exist in Singapore ${ }^{30,31}$ with the highest age-adjusted rates of hip fractures reported to be amongst the Chinese. However, median concentrations of $25(\mathrm{OH}) \mathrm{D}$ levels in Malays and Indians have been shown to be significantly lower than in the Chinese, suggesting that there exist differences in the regulation of bone health by $25(\mathrm{OH}) \mathrm{D}$ and $\mathrm{iPTH}$ and that other factors may also affect the pathogenesis of osteoporotic hip fractures in different ethnic populations. In our study, ethnicity was not found to be correlated with the type of hip fracture. It is difficult to draw further conclusions due to the small number of Malays and Indians included in the study.

Our study did not reveal any significant difference in total hip (TH) or neck of femur (NOF) BMDs between patients with trochanteric or femoral neck fractures. Earlier studies have reported mixed results: some noted lower BMD at the trochanter in patients with trochanteric fractures, while others observed lower BMD at the NOF in this fracture type. ${ }^{32-36}$ Interestingly, an earlier study from Singapore did not show any significant difference in BMD at the femoral neck between these two types of hip fractures. ${ }^{37}$

In our study, male patients frequently had trochanteric fractures. A similar finding was reported in a previous study, where the proportion of femoral neck fractures was higher in females. ${ }^{1}$ However, a significant difference in the proportion of trochanteric fractures between men and women was not found in a Norwegian study. ${ }^{38}$ The differences in observations may be explained by methodological variations as well as by problems in classification of fractures. The Norwegian study included subtrochanteric fractures and basal cervical fractures among the trochanteric fractures, while we only included intertrochanteric and fractures involving the trochanters.

We observed that women with trochanteric fractures were older than those with femoral neck fractures. This trend was not observed in men. This is in agreement with other studies that noted a rise in the proportion of intertrochanteric fractures in women with increasing age, but not in men. ${ }^{38-40}$ The reason for the gender difference and age trend is still unclear. The two major femoral sites have been found to have a dissimilar composition, with the trochanteric region having a greater proportion of trabecular bone, and the femoral neck predominantly cortical. ${ }^{41}$ The age-related loss of trabecular and cortical bone may differ between men and women, so that the higher proportion of intertrochanteric fractures in older women may reflect greater trabecular bone loss with age. ${ }^{42}$

The mean body weight of women with femoral neck fractures was found to be higher than those with trochanteric fractures in two previously published studies. ${ }^{33,43}$ The investigators of these studies attributed the finding of lower body weight in trochanteric fracture patients to lower BMD. In contrast, another study did not find any statistically significant difference in weight or BMI between patients with femoral neck and trochanteric fractures. ${ }^{4}$ In our study, the heavier patients tended to have trochanteric fractures, but this correlation was not evident on logistic regression. This suggests that body 
weight does not play a role in the differential development of hip fractures in our population.

Our study has a few limitations. The patients included were not randomly recruited. We did not have information on fall history, which may have played a role in the preferential development of one type of hip fracture over the other. Previous studies have not shown any difference between trochanteric and cervical fractures with respect to fall energy or fall characteristics, and fall biomechanics did not appear to determine the location of hip fracture. ${ }^{33,34}$ Nevertheless, the strengths of our study included the recruitment of consecutive unselected patients with osteoporotic hip fracture, the wide range of laboratory tests employed, and the availability of BMD data in a significant percentage of patients. Since the study subjects were those included in the protocolized hip fracture pathway, all laboratory tests were done within 24 to 48 hours of admission, and were analysed on the day of collection. This minimized potential errors in the collection of specimens and interpretation of the test results.

\section{CONCLUSION}

The present study is the first of its kind that examined the differential characteristics underlying the two main types of hip fracture in a population residing in a South East Asian country. Our findings suggest that the interplay between $25(\mathrm{OH}) \mathrm{D}$ and other parameters of bone metabolism in the development of the two types of hip fractures is different in our population. It is likely that lifestyle factors, in addition to structural, geometric and material properties of bone, play a more important role in the determination of the type of hip fracture that individuals are likely to develop. These observations need to be confirmed in larger prospective studies.

\section{Disclosures}

The authors have no conflicts of interests or industrial links to disclose.

\section{References}

1. Pulkkinen P, Eckstein F, Lochmüller EM et al. Association of geometric factors and failure load level with the distribution of cervical vs. trochanteric hip fractures. J Bone Miner Res 2006;21(6):895-901.

2. Szulc P, Duboeuf F, Schott AM et al. Structural determinants of hip fracture in elderly women: Re-analysis of the data from the EPIDOS study. Osteoporos Int 2006;17(2):231-6.

3. Dretakis OE, Margioris AN, Tsatsanis C et al. Elderly patients with trochanteric hip fracture have lower serum vitamin D levels compared to patients with cervical hip fracture. Arch Gerontol Geriatr 2011;52(1):e15-8.

4. Fisher A, Srikusalanukul W, Davis $\mathrm{M}$ et al. Hip fracture type: Important role of parathyroid hormone (PTH) response to hypovitaminosis D. Bone 2010;47(2):400-7.

5. Francis RM, Peacock M, Barkworth SA. Renal impairment and its effect on calcium metabolism in elderly women. Age Ageing 1984;13(1):14-20.

6. Lips P. Vitamin D deficiency and secondary hyperparathyroidism in the elderly: Consequences for bone loss and fractures and therapeutic implications. Endocr Rev 2001;22(4):477-501.
7. Rejnmark L, Vestegaard P, Brot $\mathrm{C}$ et al. Parathyroid response to vitamin D insufficiency: Relations to bone, body composition and to lifestyle characteristics. Clin Endocrinol (Oxf) 2008;69(1):29-35.

8. Rahman SA, Chee WSS, Yassin Z et al. Vitamin D status among postmenopausal Malaysian women. Asia Pac J Clin Nutr 2004;13(3):25560.

9. Wat WZ, Leung JY, Tam S et al. Prevalence and impact of vitamin D insufficiency in southern Chinese adults. Ann Nutr Metab 2007;51(1):59-64.

10. Nakamura $\mathrm{K}$, Tsugawa $\mathrm{N}$, Saito $\mathrm{T}$ et al. Vitamin $\mathrm{D}$ status, bone mass and bone metabolism in home-dwelling postmenopausal Japanese women: Yokogoshi study. Bone 2008;42(2):271-7.

11. Chailurkit LO, Kruavit A, Rajatanavin R. Vitamin D status and bone health in healthy Thai elderly women. Nutrition 2011;27(2):160-4.

12. Raso AA, Navarra SV, Li-Yu et al. Survey of vitamin D levels among post-menopausal Filipino women with osteoporosis. Int J Rheum Dis 2009;12(3):225-9.

13. Ho-Pham LT, Nguyen ND, Lai TQ et al. Vitamin D status and parathyroid hormone in an urban population in Vietnam. Osteoporos Int 2011;22(1):241-8.

14. Arya V, Bhambri R, Godbole $\mathrm{MM}$ et al. Vitamin $\mathrm{D}$ status and its relationship with bone mineral density in healthy Asian Indians. Osteoporos Int 2004;15(1):56-61.

15. Cauley JA, Lacroix AZ, Wu L et al. Serum 25-hydroxyvitamin D concentrations and risk for hip fractures. Ann Int Med 2008;149(4):242-50.

16. van Schoor NM, Visser M, Pluijm SM et al. Vitamin D deficiency as a risk factor for osteoporotic fractures. Bone 2008;42(2):260-6.

17. Pieper CF, Colon-Emeric C, Caminis J et al. Distribution and correlates of serum 25-hydroxyvitamin D levels in a sample of patients with hip fracture. Am J Geriatr Pharmacother 2007;5(4):33540.

18. Bischoff-Ferrari HA, Can U, Staehelin HB et al. Severe vitamin D deficiency in Swiss hip fracture patients. Bone 2008;42(3):597-602.

19. Roddam AW, Neale R, Appleby P et al. Association between plasma 25-hydroxyvitamin D levels and fracture risk: The EPIC-Oxford study. Am J Epidemiol 2007;166(11):1327-36.

20. Cummings SR, Browner WS, Bauer D et al. Endogenous hormones and the risk of hip and vertebral fractures among older women. Study of the Osteoporotic Fractures Research Group. N Engl J Med 1998;339(11):733-8

21. Pun KK, Wong FH, Wang C et al. Vitamin D status among patients with fractured neck of femur in Hong Kong. Bone 1990;11(5):365-8.

22. Pramyothin $\mathrm{P}$, Techasurungkul S, Lin J et al. Vitamin D status and falls, frailty, and fractures among postmenopausal Japanese women living in Hawaii. Osteoporos Int 2009;20(11):1955-62.

23. Chandran M, Hoeck HC, Wong HC et al. Vitamin D status and its relationship with bone mineral density and parathyroid hormone in Southeast Asian adults with low bone density. Endocr Pract 2011;17(2):226-34.

24. Bruce DG, St John A, Nicklason F et al. Secondary hyperparathyroidism in patients from Western Australia with hip fracture: Relationship to type of hip fracture, renal function and vitamin D deficiency. J Am Geriatr Soc 1999;47:354-9.

25. Sahota O, Gaynor K, Harwood RH et al. Hypovitaminosis D and 'functional hypoparathyroidism' - the NoNoF (Nottingham Neck of Femur) study. Age Ageing 2001;30(6):467-72.

26. Harris SS. Vitamin D and African Americans. J Nutr 2006;136(4):11269.

27. Bischoff-Ferrari HA, Dietrich T, Orav EJ et al. Positive association between 25-hydroxy vitamin $\mathrm{D}$ levels and bone mineral density: A population-based study of younger and older adults. Am J Med 2004;116(9):634-9.

28. Gutiérrez OM, Farwell WR, Kermah D et al. Racial differences in the relationship between vitamin $\mathrm{D}$, bone mineral density and parathyroid hormone in the National Health and Nutrition Examination Survey. Osteoporos Int 2011;22(6):1745-53.

29. Department of Statistics. Singapore census of population 2000: Statistical release 1 -demographic characteristics. Singapore Ministry of Trade and Industry. http://www.singstat.gov.sg/pubn/ popn/c2000sr1/t1-7.pdf.

30. Koh LK, Saw SM, Lee JJ et al. Hip fracture incidence rates in Singapore 1991-1998. Osteoporos Int 2001;12(4):311-8.

31. Hawkins RC. 25-OH vitamin D3 concentrations in Chinese, Malays and Indians. Clin Chem 2009;55(9):1749-51 
32. Vega E, Mautalen C, Gómez H et al. Bone mineral density in patients with cervical and trochanteric fractures of the proximal femur. Osteoporos Int 1991;1(2):81-6.

33. Eriksson SA, Widhe TL. Bone mass in women with hip fracture. Acta Orthop Scand 1988;59(1):19-23.

34. Nakamura N, Kyou T, Takaoka $\mathrm{K}$ et al. Bone mineral density in the proximal femur and hip fracture type in the elderly. J Bone Min Res 1992;7(7):755-9.

35. Greenspan SL, Myers ER, Maitland LA et al. Trochanteric bone mineral density is associated with type of hip fracture in the elderly. J Bone Min Res 1994;9(12):1889-94.

36. Mautalen CA, Vega EM, Einhorn TA. Are the etiologies of cervical and trochanteric hip fractures different? Bone 1996;18(3 Suppl):133S$7 \mathrm{~S}$.

37. Goh JCH, Bose K, Das De S. Pattern of fall and bone mineral density measurement in fractures. Ann Acad Med Singapore 1996;25(6):820-3.

38. Bjørgul K, Reikerås $\mathrm{O}$. Incidence of hip fracture in southeastern Norway: A study of 1,730 cervical and trochanteric fractures. Int Orthop 2007;31(5):665-9.

39. Tanner DA, Kloseck M, Crilly RG et al. Hip fracture types in men and women change differently with age. BMC Geriatr 2010;10:12.
40. Karagas MR, Lu-Yao GL, Barrett JA et al. Heterogeneity of hip fracture: Age, race, sex and geographic patterns of femoral neck and trochanteric fractures among the US elderly. Am J Epidemiol 1996;143(7):677-82.

41. Riggs BL, Wahner HW, Seeman E et al. Changes in bone mineral density of the proximal femur and spine with aging. Differences between the postmenopausal and senile osteoporosis syndromes. J Clin Invest 1982;70(4):716-23.

42. Dennison E, Eastell R, Fall CH et al. Determinants of bone loss in elderly men and women: A prospective population-based study. Osteoporos Int 1999;10(5):384-91.

43. Partanen J, Heikkinen J, Jämsä $\mathrm{T}$ et al. Characteristics of lifetime factors, bone metabolism and bone mineral density in patients with hip fracture. J Bone Miner Metab 2002;20(6):367-75.

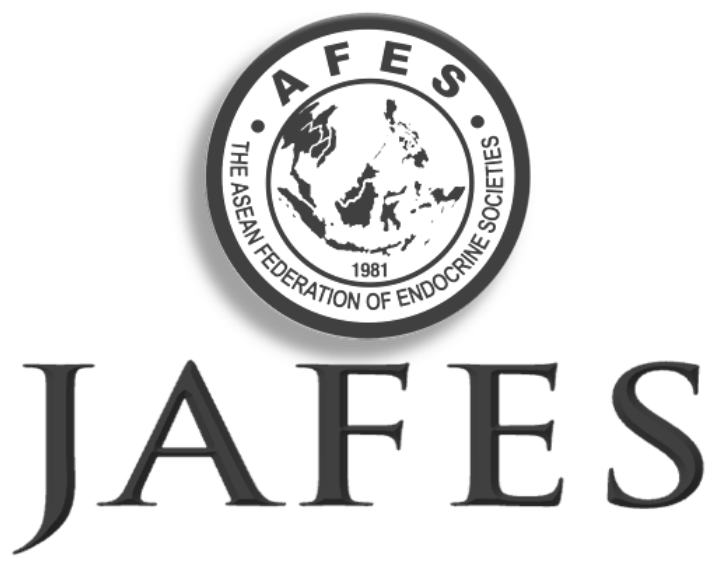

\section{Send your paper to the publication pathway. Instructions to Authors at www.ASEAN-endocrinejournal.org.}

